\title{
ANALYSIS OF PHYSICAL PROPERTIES OF DIETARY FIBER FROM APPLE WASTE
}

\author{
Sławomir OBIDZIŃSKI, Magdalena DOŁŻYŃSKA, Sylwia LEWICKA \\ Białystok University of Technology, Faculty of Civil and Environmental Engineering, POLAND \\ E-mail of corresponding author: s.obidzinski@pb.edu.pl
}

Keywords: apple waste, pressure agglomeration, pellet from agri-food waste

\begin{abstract}
The purpose of the present study was to determine the suitability of apple fibers (dietary fiber) as a raw material for granulate pellets production, as an aspect of waste management in sustainable agriculture processes. Apple fibers are a waste produced during the agri-food processing of apples. It is obtained from apple peas and can be further used as a diet supplement or for animal feed purposes, reducing the breeding costs. The material was moisturized with water and a mixture of water and milk powder to a moisture content of $16 \%$. During the tests, the maximum pressure of the process was determined for all trials carried out. Density, absorption and activity of water in the resulting agglomerate and in the raw material were examined. Increasing the temperature of the pressure process from 20 to $50^{\circ} \mathrm{C}$ results in an approx. $50 \%$ increase in the density of the test mixtures. Higher density of the resulting granules was obtained using lower agglomeration pressure. The increase in density of the granulate influences the reduction of its water absorption (decrease of its moisture content and water activity). Increasing the density of apple fiber (from loose fiber) decreases moisture and water activity.
\end{abstract}

\section{INTRODUCTION}

Agricultural residues are the largest, in terms of mass, biomass feedstock in the Word, which is about $1.5 \mathrm{Gt}$ of straw from cereal crops produced worldwide. According to Lu et al. (2014) densification (agglomeration) of biomass is considered important to achieve economical handling, transport, and storage procedures. Hejft (2002) claims that the main goal of agglomeration pressure processes is to obtain a compact and fragmentary product of a defined shape, geometric dimensions and properties. This process is influenced by many factors: the characteristics of the bulk medium, the way it is prepared for compacting, the type of device in which the process is implemented and the parameters of the agglomeration process. According to Janewicz and Kostrukiewicz (2016), the direct impact on the course and effects of the agglomeration process of a given bulk material is its susceptibility to densification and its ability to merge. These properties can be shaped by, for example, the use of binders. For example, Lu et al. (2014) investigated that with the addition of wood residue the tensile strength of the wheat straw pellets increased, other described experiments show that the density of wheat straw pellets was increased by adding bentonite and lignosulfonate. Ahn et al. (2014) concluded that the addition of rapeseed flour, coffee meal and lignin powder to larch or tulip tree particles increase the durability of obtained pellets. Whittaker and Shield (2017) reviewed factors affecting biomass pellet quality and they fund that starch or lignin-based binders can improve durability, particularly in feedstocks with lower lignin contents. Moreover, adding fat or oil-based binders might reduce the energy consumption of agglomeration, but the reduced friction may cause the pellets more elastic and less durable. Soleimani et al. (2017) state that pellets from spruce wood shavings or wheat straw with binders like glucose, fructose, sucrose or maltodextrin have higher density over $1200 \mathrm{~kg} / \mathrm{m}^{3}$ or even $1300 \mathrm{~kg} / \mathrm{m}^{3}$, where compared to the unit density of the pellets from the native biomass it was up to $1200 \mathrm{~kg} / \mathrm{m}^{3}$. Bai et al. (2017) obtained good quality pellets from biochar and $15 \%$ additive of peanut shell binder. 
Similar research was conducted by Hu et al. (2015) where to biochar were added lignin, starch, calcium hydroxide, and sodium hydroxide. They found that starch was not suitable to be used as a binder cause of the low mechanical strength and density of obtained pellets.

The aim of the presented paper is to analyze the suitability of apple fibers (dietary fiber) as a raw material for granulate pellet production, as an aspect of waste management in sustainable agriculture processes. Apple fibers in the forms of pellets may be used as a diet supplement or for animal feed purposes, which would reduce the costs of agri-food production. Apple fibers were agglomerated in various temperature conditions from 20 to $50^{\circ} \mathrm{C}$ and using water or water and milk powder as a binder. The obtained pellets were examined on maximum agglomeration pressures, density, water absorption and water activity.

\section{MATERIALS AND METHODS}

The material used in the experiment was dietary fiber from apple waste. Apple fiber is a loose product used to produce from apple pomace pieces. Fiber production takes place through multi-phase cleaning, grinding, micronization and pasteurization. It is characterized by a high content of organic acids, vitamins, pectins and tannins. This means that it consists predominantly of soluble fiber. The apple fiber had moisture content of $8.1 \%$ and was mixed with water and water and milk powder to increase the humidity to $16 \%$.

In the course of the tests of the densification process, determined were: the susceptibility to densification of dietary fiber from apple waste mixed with water and water with milk powder, by determining the maximum pressures densifying the material and the density of obtained pellets. Moreover, there was examined the water activity and water absorption of the raw material and produced pellets.

Tests of the densification process were carried out on a SS-3 stand, with the "open densification chamber-densifying piston" working system presented in the articles (Obidziński 2012a, Obidziński 2012b). The stand was modernized by using a heating band coupled with a temperature controller. Densification of the material was carried out by means of piston equipped with tensometric sensor allowing to record forces acting on the piston.

In the course of the tests, 20 samples were subject to densification in an open chamber with a diameter of $8 \mathrm{~mm}$. The tests of densification of apple fiber waste were carried out at two input values, i.e.:

$-\mathrm{x}_{1}=\mathrm{z}_{\mathrm{w}}-$ binder type (water, water with milk powder),

- $\mathrm{x}_{2}=\mathrm{t}_{\mathrm{p}}$ - process temperature $\left(20,35\right.$ and $\left.50^{\circ} \mathrm{C}\right)$.

The tests were carried out at a length of matrix openings of $1_{\mathrm{m}}=20 \mathrm{~mm}$ by densifying waste samples with a mass of $\mathrm{m}_{\mathrm{p}}=0.7 \mathrm{~g}$.

Pellets density was determined, after 24 hours, by measuring the height and diameter of pellets using means of a caliper with an accuracy of $\pm 0.02 \mathrm{~mm}$ and determining their mass using means of a WPS 360 laboratory scale with an accuracy of $\pm 0.001 \mathrm{~g}$. Density was calculated as the ratio of the mass of pellets to the sum of their volumes. Determination of the moisture content of material was performed pursuant to PN-76/R- 
64752, prior to the densification process, using means of a WPE 300S moisture balance with an accuracy of $0.01 \%$. Water activity of pellets was measured after 120, 240 and 360 hours of its storage in desiccators in various salinity conditions, using the AquaLab Series 3 apparatus, the methodology was before described in articles (Obidziński 2014, Obidziński et al. 2017).

\section{RESULTS}

Initial tests allowed to conclude that the tested apple fiber is characterized by bulk density of approx. $554.31 \mathrm{~kg} / \mathrm{m}^{3}$ and its water activity is 0.510 . Table 1 presents the experimental data obtained during the agglomeration process of apple fiber. It was observed that in the case of density, the type of used binder did not affect it significantly in any process temperature. Completely different was in the case of the agglomeration pressures (fig.1.): it was found that water with milk powder as a binder requires greatly lower pressure to achieve a similar density as pellets produced from fiber and water. Moreover, increasing the process temperature had notably decreased the agglomeration pressure, while, as expected, the density increased.

Table 1. Results of granulate density tests and maximum pressures obtained during the pressure process of apple fiber agglomeration with the addition of various binders

\begin{tabular}{|c|c|c|c|c|}
\hline \multirow{2}{*}{$\begin{array}{c}\text { Temperature } \\
{\left[{ }^{\circ} \mathrm{C}\right]}\end{array}$} & \multicolumn{2}{|c|}{ Pellet density $\left[\mathrm{kg} / \mathrm{m}^{3}\right]$} & \multicolumn{2}{c|}{$\begin{array}{c}\text { Maximum agglomeration pressure } \\
\text { [MPa] }\end{array}$} \\
\cline { 2 - 5 } & Pellet with water & $\begin{array}{c}\text { Pellet with water and } \\
\text { milk powder }\end{array}$ & Pellet with water & $\begin{array}{c}\text { Pellet with water } \\
\text { and milk powder }\end{array}$ \\
\hline 20 & 804.866 & 809.231 & 52.15 & 16.95 \\
\hline 35 & 1003.259 & 1008.542 & 21.61 & 10.69 \\
\hline 50 & 1202.922 & 1210.875 & 7.36 & 6.32 \\
\hline
\end{tabular}

Table 2 presents results of pellet water absorption in various cases of binder used, $\mathrm{NaCl}$ concentration in a desiccators and pellet density. It has been found that pellets produced from apple fiber and water with milk powder are more susceptible for water absorption, especially at their low density. On the other hand, pellets with high density had a higher moisture content after the experiment which was, for example for water and milk powder as a binder approx. $13 \%$ for $1200 \mathrm{~kg} / \mathrm{m}^{3}$ and $10 \%$ for $800 \mathrm{~kg} / \mathrm{m}^{3}$ : the higher density the higher water sorption during the agglomeration processes.

Table 2. Changes in pellet humidity during its for 360 hours storage in desiccators in various salinity conditions

\begin{tabular}{|l|c|c|c|c|c|c|c|c|c|}
\hline $\mathrm{NaCl}$ concentration [\%] & \multicolumn{3}{|c|}{25} & \multicolumn{3}{c|}{30} & \multicolumn{3}{c|}{35} \\
\hline Approx. pellet density [kg/m ${ }^{3}$ ] & 800 & 1000 & 1200 & 800 & 1000 & 1200 & 800 & 1000 & 1200 \\
\hline $\begin{array}{l}\text { Change in pellet humidity (binder water } \\
\text { and milk powder) [\%] }\end{array}$ & 1.3 & 0.5 & 0.3 & -0.3 & -0.4 & -0.3 & -0.4 & -0.4 & -0.5 \\
\hline $\begin{array}{l}\text { Change in pellet humidity (binder } \\
\text { water) [\%] }\end{array}$ & 0.9 & 0.9 & 0.2 & -0.3 & -0.4 & -0.6 & -0.2 & -0.5 & -0.6 \\
\hline
\end{tabular}




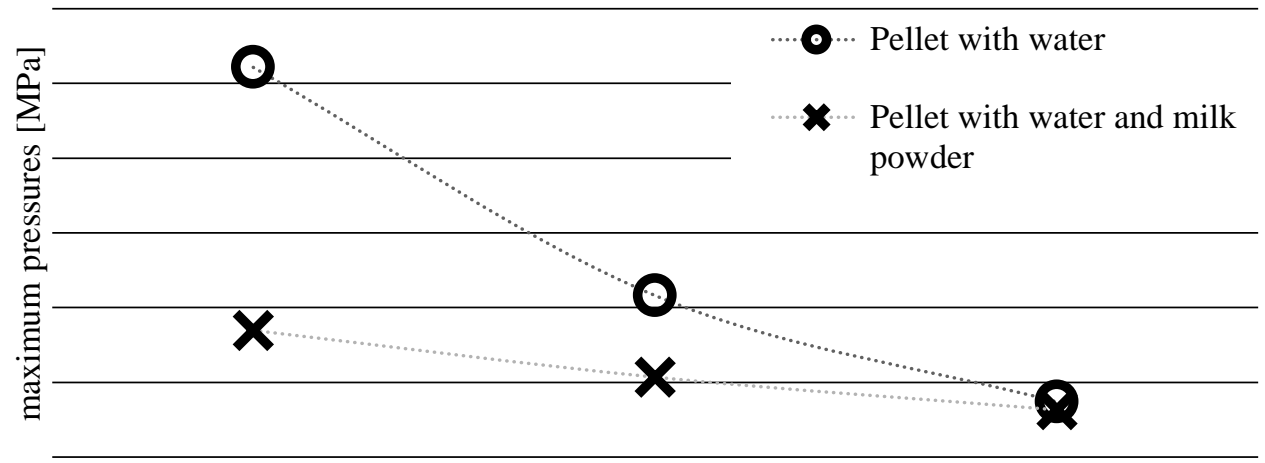

temperature $\left[{ }^{\circ} \mathrm{C}\right]$

Figure 1. Influence of the temperature of the agglomeration process on the maximum thickening pressures obtained during the process of apple fiber agglomeration with the addition of various binders

In figures 2 and 3 are presented the effect of the residence time in the desiccators with various concentrations of $\mathrm{NaCl}$.

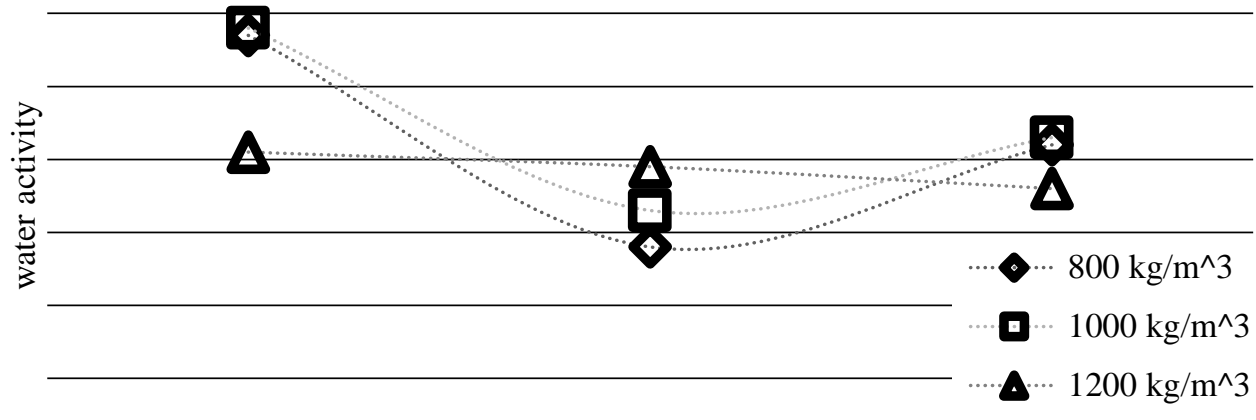

concentrations of $\mathrm{NaCl}$ solution in the desiccators

Figure 2. Effect of the residence time of a sample of apple-fiber granulate with added water and milk powder as binder obtained during the agglomeration pressure process and the density of tested granulate on water activity at different concentrations of $\mathrm{NaCl}$ solution in the desiccators (after $360 \mathrm{~h}$ )

The analysis of figure 2 and 3 shows that the increase in density of granules from 800 to $1200 \mathrm{~kg} / \mathrm{m}^{3}$ influences the increase in water activity. For example, with a residence time of 72 hours in a desiccator and a concentration of $25 \%$ hydrochloric solution, increasing the density of granules with water from 800 to $1200 \mathrm{~kg} / \mathrm{m}^{3}$ influences the increase in water activity from 0.677 to 0.744 . 


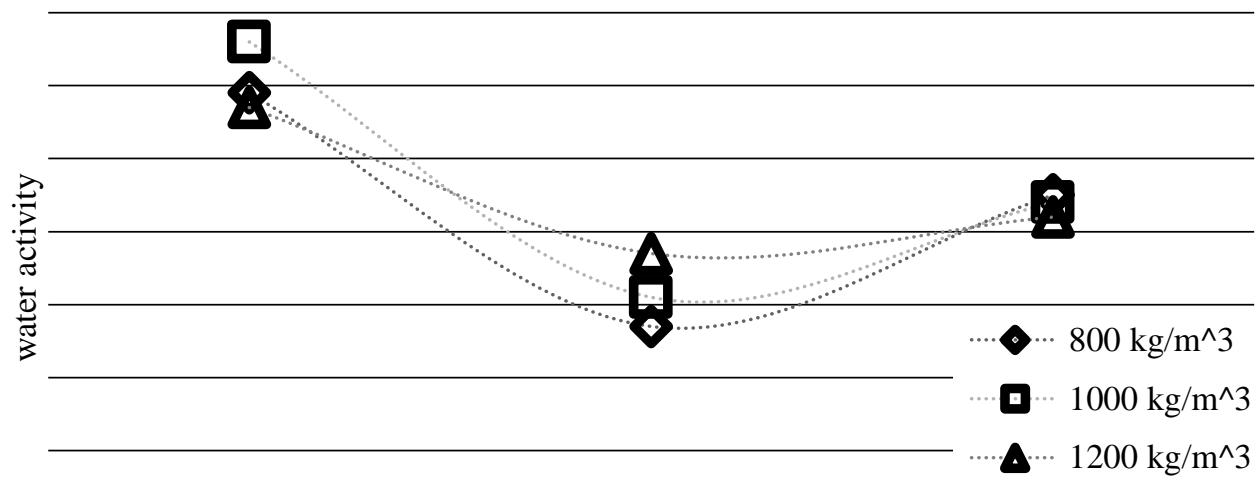

concentrations of $\mathrm{NaCl}$ solution in the desiccators

Figure 3. Effect of the residence time of a sample of apple-fiber granulate with added water as binder obtained during the agglomeration pressure process and the density of tested granulate on water activity at different concentrations of $\mathrm{NaCl}$ solution in the desiccators (after 360h)

Greater water activity was characterized by fiber granules with added water, less - with the addition of milk powder. The highest water activity values differ only 0.004 . They are 0.740 for powdered milk granules and 0.744 for granules with water. They were recorded after 360 hours of storage, for a $1200 \mathrm{~kg} / \mathrm{m}^{3}$ granulate, in a $25 \% \mathrm{NaCl}$ desiccator. The smallest values were recorded for granules of $800 \mathrm{~kg} / \mathrm{m}^{3}$, after storing 72 hours in a $35 \% \mathrm{NaCl}$ desiccator. For powdered milk granules this value is 0.598 , for water granules 0.615 . The results conduct that only $800 \mathrm{~kg} / \mathrm{m}^{3}$ granules stored for 72 hours in a $35 \% \mathrm{NaCl}$ desiccator are biological safety. Other specimens are exposed to fungus and yeast. Basing on the results obtained (table 2 and figure 2 and 3), it was found that increasing the density of apple fiber (from loose fiber, through the granulate obtained without pressure to the pressure granulate) decreases the increase in moisture and water activity during storage in the desiccator in the presence of $\mathrm{NaCl}$ solution.

\section{CONCLUSIONS}

Based on the results obtained, it has been found that increasing the temperature of the pressure compaction from 20 to $50^{\circ} \mathrm{C}$ results in a decrease in the thickening pressures in both, with water binder and powdered milk binder and increases the density of the resulting granulate. Thus, the pressure of the dietary apple fiber agglomeration with the water binder requires higher compaction pressures than in the case of thickening of the binder fiber with a solution of water and milk powder. The increase in the density of the granulate obtained by pressure agglomeration results in a decrease of its water absorption (decrease of its moisture content and water activity during the presence of $\mathrm{NaCl}$ solution). It was also found that the moisture content and activity of the loose fiber water increases with increasing the fiber's storage time in the desiccator (with $\mathrm{NaCl}$ solution): increasing the storage time of the loose fiber in the desiccator from 5 days to 15 days causes an increase in its moisture content and water activity. $\mathrm{NaCl}$ in the desiccator influences the decrease in water absorption of stored pellets. Water-based fiber granules exhibit higher moisture content and water activity during the presence of $\mathrm{NaCl}$ solution in relation to the powdered milk granulate at each density tested and at each $\mathrm{NaCl}$ concentration in the desiccator. Further processing of apple fibers, in the 
form of pellets, for diet supplement or for animal feed purposes will reduce agriculture production costs.

\section{REFERENCES}

Ahn B.J., Chang H., Lee S.M., Choi D.H., Cho S.T., Han G., Yang I. (2014). Effect of binders on the durability of wood pellets fabricated from Larix kaemferi C. and Liriodendron tulipifera L. sawdust. Renewable Energy, (62), 18-23.

Bai X., Wang G., Gong C., Yu Y., Liu W., Wang D. (2017). Co-pelletizing characteristics of torrefied wheat straw with peanut shell. Bioresource Technology, (233), 373-381.

Hu Q., Shao J., Yang H., Yao D., Wang X., Chen H. (2015). Effects of binders on the properties of biochar pellets. Applied Energy, (157), 508-516.

Hejft R. (2002). Ciśnieniowa aglomeracja materiałów roślinnych.

Janewicz A., Kosturkiewicz B. (2016). Analysis of compressibility and compactibility of lignite and biomass mixture powder. Przemyst Chemiczny, (95/8), 1482-1484.

Lu D., Tabil L.G., Wang D., Wang G., Emami S. (2014). Experimental trials to make wheat straw pellets with wood residue and binders. Biomass and Bioenergy, (69), 287-296.

Obidzinski S. (2012a) Analysis of usability of potato pulp as solid fuel. Fuel Processing Technology, (94), 67-74.

Obidziński S. (2012b) Pelletization process of postproduction plant waste. International Agrophisics, (26(3)), 279-284.

Obidzinski S. (2014). Utilization of post-production waste of potato pulp and buckwheat hulls in the form of pellets. Polish Journal of Environmental Studies. 2014, Vol. 23(2014), 1391-1395.

Obidziński S., Joka M., Luto E., Bieńczak A. (2017). Research of the densification process of postharvest tobacco waste. Journal of Research and Applications in Agricultural Engineering, (62(1)), 149154.

Soleimani M., Tabil X.L., Grewal R., Tabil L.G. (2017). Carbohydrates as binders in biomass densification for biochemical and thermochemical processes Fuel, (193), 134-141.

Whittaker C., Shield I. (2017). Factors affecting wood, energy grass and straw pellet durability - A review. Renewable and Sustainable Energy Reviews, (71), 1-11. 